\title{
A ESCOLA COMO ESPAÇO DE MEDIAÇÃO DO CONHECIMENTO E HUMANIZAÇÃO
}

\author{
Everton Carlos Crema \\ Universidade Estadual do Paraná (UNESPAR), Brasil \\ E-mail: evertoncrema@yahoo.com.br \\ ORCID: https://orcid.org/0000-0002-1931-6019
}

Data de recebimento: $28 / 01 / 2020$

Data de aprovação: 25/03/2020

DOI: https://doi.org/10.30612/frh.v22i39.12570

\begin{abstract}
Resumo: O debate proposto busca discutir o papel e a importância da escola como um espaço de mediação e transmissão cultural, a partir da síntese dos conhecimentos científicos escolares e os saberes e experiências sociais, ou pelo menos assim deveria ser. A cultura escolar, resultado dos processos de escolarização e a cultura social produzida na vida prática, devem necessariamente se relacionar integrando campos, estruturas e formas de concepção e compreensão do mundo. Poucos lugares sociais possuem a diversidade e a representatividade da escola, essa condição também se apresenta como uma possibilidade e um imperativo categórico, na construção de uma sociedade mais justa, tolerante, equitativa e democrática. Para isso, nossos professores precisam aprender melhor, como podem ensinar com mais eficiência e eficácia e precisam de formação contínua, ante os desafios e dilemas da educação. Nossas alunas e alunos precisam 'reaprender' a aprender, valorizando seus conhecimentos sociais e histórias de vida, também formas de saber, orientando as carências na vida prática. A escola em sua diversidade e pluralidade se tornou um lugar onde se pode 'existir' e a educação é o conteúdo dessa 'resistência' contra o abuso, preconceito, racismo e toda a violência, a escola tem que ser melhor, porque nossos alunos e alunas precisam ser melhores. O conhecimento aprendido/construído sobre a vida e a diversidade, cria uma qualidade explicativa /compreensiva superior, transformando a própria realidade, ou no mínimo parâmetros compreensivos mais coerentes. Como resultado construiremos uma sociedade que refletirá a escola e não o contrário.
\end{abstract}

Palavras-chave: Metodologias de ensino; Ensino da diversidade; Cultura escolar e cultura social; humanismo diverso.

\section{SCHOOL AS A SPACE FOR MEDIATING KNOWLEDGE AND HUMANIZATION}

Abstract: The proposed debate seeks to discuss the role and importance of the school as a space for mediation and cultural transmission, based on the synthesis of school scientific knowledge and social knowledge and experiences, or at least it should be so. School culture, the result of schooling processes and the social culture produced in practical life, must necessarily relate to each other by integrating fields, structures and ways of conceiving and understanding the world. Few social places have the diversity and representativeness of the school, this condition also presents itself as a possibility 
and a categorical imperative, in the construction of a more just, tolerant, equitable and democratic society. For this, our teachers need to learn better, how they can teach more efficiently and effectively and need continuous training, in the face of the challenges and dilemmas of education. Our students need to 'relearn' how to learn, valuing their social knowledge and life stories, as well as ways of knowing, guiding the needs in practical life. The school in its diversity and plurality has become a place where one can 'exist' and education is the content of this 'resistance' against abuse, prejudice, racism and all violence, the school has to be better, because our students need be better. The knowledge learned / constructed about life and diversity, creates a superior explanatory / comprehensive quality, transforming reality itself, or at least more coherent comprehensive parameters. As a result, we will build a society that will reflect the school and not the other way around.

keywords: Teaching methodologies; Teaching Diversity; School Culture and Social Culture; Diverse Humanism.

\section{LA ESCUELA COMO ESPACIO PARA MEDIAR EL CONOCIMIENTO Y LA HUMANIZACIÓN}

Resumen: El debate propuesto busca discutir el papel y la importancia de la escuela como un espacio de mediación y transmisión cultural, basado en la síntesis del conocimiento científico de la escuela y el conocimiento y las experiencias sociales, o al menos así debería ser. La cultura escolar, el resultado de los procesos escolares y la cultura social producida en la vida práctica, debe estar necesariamente relacionada mediante la integración de campos, estructuras y formas de concebir y comprender el mundo. Pocos lugares sociales tienen la diversidad y representatividad de la escuela, esta condición también se presenta como una posibilidad y un imperativo categórico, en la construcción de una sociedad más justa, tolerante, equitativa y democrática. Para esto, nuestros maestros necesitan aprender mejor, cómo pueden enseñar de manera más eficiente y efectiva y necesitan capacitación continua, frente a los desafíos y dilemas de la educación. Nuestros estudiantes necesitan "volver a aprender" cómo aprender, valorando su conocimiento social y sus historias de vida, también formas de saber, guiando las necesidades en la vida práctica. La escuela en su diversidad y pluralidad se ha convertido en un lugar donde uno puede 'existir' y la educación es el contenido de esta 'resistencia' contra el abuso, los prejuicios, el racismo y toda violencia, la escuela tiene que ser mejor, porque nuestros estudiantes necesitan se mejor El conocimiento aprendido / construido sobre la vida y la diversidad, crea una calidad explicativa / integral superior, transformando la realidad misma, o al menos parámetros integrales más coherentes. Como resultado, construiremos una sociedad que reflejará la escuela y no al revés.

Palabras clave: Metodologías de enseñanza; Enseñanza de la diversidad; Cultura escolar y cultura social; Humanismo diverso. 


\section{Introdução}

Parte significativa de nossas vidas se desenvolve dentro da escola, sobretudo, durante nossa infância e adolescência, proporcionando importantes experiências, conhecimento e aprendizado, que envolvem e influenciam o que somos, pensamos e fazemos. Muito se discutiu em relação ao papel da escola como produtora ou reprodutora do conhecimento, entendemos aqui e no encaminhamento da discussão, que a escola produz e reproduz conhecimento em mediação e em diversidade. Essa dialogia do que deve permanecer em termos de conhecimento, bem como, aquilo que deve mudar ou evoluir, envolve um dos mais importantes debates educacionais.

Propositivamente o conhecimento não é neutro do ponto de vista político ou social, seus saberes criam e movimentam interesses e realidades, espelhando um arquétipo típico social. Portanto, a validade do conhecimento, do que se ensina nas escolas às próximas gerações deve encontrar assento em um ensino humanista, pautado em valores éticos, plurais e democráticos. Não se trata de questionarmos o currículo naquilo que se ensina, ainda que isso também seja importante e necessário, mas sim criticar e transformar o como, e com qual significado e direção devemos e precisamos ensinar.

O humanismo atribui aos homens do passado a liberdade de autodeterminação. Ele vincula a esse ponto de vista o entendimento de outras formas de vida, alheias. Uma hermenêutica histórica torna possível que formas diferentes de vida reflitam umas às outras e se compreendam, de modo que o olhar sobre a alteridade dos outros permita reconhecer a singularidade do próprio eu (RÜSEN, 2015, p. 173).

Aceita a condição e importância do devir histórico, a escola e o ensino precisam adotar como uma atitude e conteúdo pedagógico, a mediação do conhecimento científico e do conhecimento social, para se fazer presente em sociedade e para que essa sociedade se perceba representada dentro da escola. O formalismo do conhecimento, dentro das disciplinas escolares não pode deixar de fitar os contextos, problemas e demandas sociais como meio e condição da validade do conhecimento e princípio ético fundamental. As diversidades sexuais, ético-raciais e as relações de gênero, existem e participam da história e precisam ser compreendidas dentro dos seus próprios percursos e contextos. Desnaturalizar, negar e invisibilizar esses grupos sociais significa retiralhes sua condição de existência, de viver, de fazer, de lutar, sem suas histórias perdem a 
materialidade de suas identidades, permanecendo em um "não ser" que não pode "resistir" sem “existir". A escola é o lugar dessa existência, a educação é o conteúdo da resistência que precisa transformar nossa sociedade, reconhecendo, respeitando e valorizando a diferença. Precisamos ser melhores, assim como canta Projota: "Quero ser melhor do que fui ontem. Melhor do que eu sou, não melhor do que você. Só o melhor que eu possa ser" (PROJOTA).

\section{A sala de aula na construção da mediação entre a cultura escolar e a cultura social}

A sala de aula é muitas coisas, ela pode ser um lugar de conhecimento, de ciência e erudição, de compartilhamento de saberes, lugar de um currículo oficial, real ou oculto, um espaço de reinvindicação se assim preferirmos, com todos os significados e renúncias que carregam consigo essas categorias, das quais não discordamos nem hierarquizamos. Entretanto essas perspectivas de entendimento por vezes são compreendidas e analisadas de forma singular, pontual e linearmente, muito em função dos modelos da epistemologia científica e suas exigências de especialização, curricularização e disciplinarização. Diferente e verdadeiramente, nos processos cotidianos de ensino aprendizado, a sala de aula é antes e acima de tudo, um lugar de mediação entre conhecimentos científicos disciplinares e conhecimentos sociais, ou se preferirmos uma cultura escolar e uma cultura social, a fim de melhor lidarmos com a amplitude, abrangência e diferenciação da cultura e conhecimento.

O processo de mediação do conhecimento escolar surge de um "hibridismo cultural" em dialogia continuada, onde os universos da "cultura escolar" e "cultura histórica" por vezes se consorciam ou antagonizam em busca de consensos explicativos e resolutivos ante as demandas do processo educativo, experiência e conhecimento social prático. Segundo Forquin (1993) a cultura escolar surge da relação da produção, reprodução do conhecimento e "transmissão cultural" com os currículos escolares e os processos pedagógicos do ensino. Como resultado o ensino aprendizado adquire um caráter específico e identidade própria, marcado pelas condições políticas em que foi gestado. Nesse sentido, a cultura escolar cria e reproduz a síntese dos entes, estruturas e

1 Conceito desenvolvido por Nestor Garcia Canclini, onde as trocas culturais não se apresentam mediadas de forma equivalente; em realidade elas se constroem em oposição desproporcional e violenta. Desproporcional porque a ideia de mediação cria um entendimento artificial de igualdade do discurso e das relações de poder, o que é inverossímil e irreal. Segundo porque as relações de força/poder se constituem em realidade de forma violenta para grupos subordinados em diversos níveis e condições, seja pela ausência de voz, seja pela imposição de modelos educacionais e curriculares. 
interesses educacionais, caracterizando as condições de permanência e mudança no campo escolar.

Todo o processo educativo, constrói e resulta do seu próprio fazer, forçado pelo peso da sua historicidade, das experiências escolares, de seu processo organizativo, currículo, da diversidade cultural e suas legitimidades, da produção da "hegemonia". As condições elencadas não buscam a idealização formal de uma homogeneidade estrutural da cultura escolar, mas sim, a descrição dos processos constitutivos de sua especificidade, que nos aproximam do seu detalhamento funcional, necessário para a compreensão dos processos de ensino aprendizado dentro das condições reais e cotidianas da sala de aula. O que do contrário, para Forquin (1993), poderia levar a uma crítica da validade da transmissão cultural.

Entretanto o pensamento pedagógico contemporâneo não pode se esquivar de uma reflexão sobre a questão da cultura e dos elementos culturais dos diferentes tipos de escolhas educativas, sob pena de cair na superficialidade. Ele se encontra, na verdade, na situação paradoxal de não poder dispensar a idéia de cultura, mas tampouco de poder utilizá-la como um conceito claro e operatório (FORQUIN, 1993, p. $10)$.

Uma análise mais detida e singularizada dos processos constitutivos da cultura escolar a partir de suas realidades e experiências no ensino aprendizagem imediatas, vão de encontro ao pensamento de Goodson (2008), ao defender que as estruturas conformativas do processo escolar são melhor compreendidas e validadas ao analisarmos as narrativas biográficas docentes em sua historicidade. Além disso, essa perspectiva se reveste de uma maior eficiência e eficácia, se pensamos as dimensões territoriais e as variedades culturais regionais em nosso país. Uma análise mais detida do processo educativo não invalida as grandes sínteses ou explicações hegemônicas a respeito do campo educacional, novamente apontamos para a necessidade de mediação entre extremos, o "macro" e o "micro".

Todo o processo educativo se realiza dentro de contextos sociais e culturais amplos, inclusive antecedido por uma "cultura histórica", que optamos aqui por chamar de "cultura social", termo mais adequado à uma análise e perspectiva restrita dentro do campo educacional, também por ensejar um universo de investigação mais preciso, ressaltando, sobretudo, a experiência e o conhecimento social cotidiano, construído a partir das demandas da vida prática. Em termos de definição, a cultura histórica surge da articulação, mesmo integração, prática e intencional em todos os contextos sociais e 
individuais, dado o papel e atributo do histórico, da subjetividade e perspectivação da consciência humana no tempo (SCHMIDT; MARTINS, 2016).

Parte da cultura social se desenvolve dentro da escola, dentro dos processos de escolarização, dado o tempo em que "convivemos" em desenvolvimento e aprendizado, orientando, mesmo construindo nossa capacidade de interpretação e orientação significativamente. Defendemos que durante o processo de escolarização e mais especificamente, nas relações de ensino aprendizagem, o conhecimento científico disciplinar se consorcia ao conhecimento social, marcadamente nos processos didáticos - metodológicos e cognitivos, tanto para professores e professoras, como para alunos e alunas, ainda que de formas diferentes.

Como resultado temos uma "mediação" entre conhecimentos científicos disciplinares e conhecimentos sociais ou mesmo suas pretensões de validade, que encontram encaminhamento pelos processos cognitivos e didático metodológicos. Portanto, torna-se fundamental que a escola e nossos/as docentes incorporem o conhecimento, realidades e demandas sociais nos processos de ensino, articulando essa "vida" aos conteúdos curriculares disciplinares. Vantagens significativas surgiriam da mediação desses "hemisférios", cognitivamente para os alunos e alunas, as condições de abstração e relação de saberes em síntese, aumentariam em qualidade e se ampliariam por diversas áreas do conhecimento, também facilitando um processo de multidisciplinariedade.

Nesse sentido pode-se dizer perfeitamente que a cultura é o conteúdo substancial da educação, sua fonte e sua justificação última: a educação não é nada fora da cultura e sem ela. Mas reciprocamente, dir-se-á que é pela e na educação, através do trabalho paciente e continuadamente recomeçado de uma "tradição docente" que a cultura se transmite e se perpetua: a educação "realiza" a cultura como memória viva, reativação incessante e sempre ameaçada, fio precário e promessa necessária da continuidade humana (FORQUIN, 1993, p. $14)$.

Para as professoras e professores a utilização da cultura social, do conhecimento e experiência social de seus alunos e alunas, junto às disciplinas escolares possuem vantagens didáticas e metodológicas significativas, tendo como resultado um processo de ensino aprendizado mais prazeroso e efetivo. Primeiramente porque os/as docentes ao se utilizarem da cultura social de seus alunos e alunas em suas aulas, permitem e constroem relações onde todos os signos, significantes e significados criam arquétipos compreensivos diversos com os conteúdos científicos disciplinares. A 
capacidade de compressão dos alunos e alunas se amplia tanto em termos de qualidade como de quantidade, pois buscam construir entendimentos a partir de suas linguagens, estética e narrativas. Os alunos e alunas ao recorrerem a estruturas compreensivas diversas, criam para si inúmeras possibilidades distintas articuladas de "construir" meios de compreensão complexa. Ao mesmo tempo, através desse processo, se desenvolvem mecanismos cognitivos comparativos dos processos de aprendizagem próprios, os alunos e alunas aprendem que podem aprender de várias formas, e são estimulados/as a desenvolverem esse conhecimento relacional próprio.

Em segundo lugar, os/as docentes ao ensinarem seus conteúdos disciplinares científicos, utilizando-se da cultura e conhecimento social, conseguem melhorar as condições e índices de eficácia na aprendizagem de seus alunos e alunas, pois em certa obviedade, aumentam as condições de entendimento e compreensão de seus alunos/as, dentro de linguagens, estética e narrativas próximas próprias e apreensíveis. Metodologicamente os/as professores/as dotam suas aulas de uma maior qualidade, pois podem melhorar e variar suas narrativas explicativas, ampliando também os níveis de interesse e atenção de seus alunos e alunas, sabemos a tempos quais são nossas maiores dificuldades em sala de aula e precisamos buscar meios resolutivos para isso.

Não diferentemente, a terceira perspectiva repousa na ação/relação simbiótica da comunidade com a escola, quando a interação desses "hemisférios" produz conhecimento, reconhecimento e transformação da vida prática, dos sentidos históricos sociais de orientação. A escola ao reconhecer e inserir a comunidade nas estruturas educativas reforça as relações de troca e participação comuns, consequentemente os canais de comunicação/ação crescem e se ampliam. Essa aproximação extremamente saudável e necessária à escola, acaba por ensejar o assentimento da comunidade aos processos educativos. Isso significa que um maior interesse da comunidade, notadamente da família, dos pais, mães e responsáveis, reforça e "institucionaliza" na "família" a importância do papel da escola, professores/as e disciplinas escolares. Quando a escola é assunto nas casas de nossas alunas e alunos, se desenvolve uma ressignificação positiva do ambiente escolar, essa valorização recoloca nossos alunos e alunas sob novos olhares, sobretudo, os próprios.

Quando a comunidade, se percebe como uma realidade, conteúdo e possibilidade educativa dentro da escola, desenvolve-se um efeito multiplicador e integrador, abrindo importantes possibilidades de trabalho conjunto. As potencialidades e problemas da comunidade encontram um encaminhamento resolutivo e solidariedade 
junto a escola, seja pela necessidade de apoio de toda ordem que a sociedade e a escola demandam, seja pelas oportunidades educativas e de intervenção da escola no corpo social, que emergem da aproximação recíproca. Quando a comunidade, famílias e nossos alunos e alunas percebem a validade e significado da educação de forma concreta, transformando suas vidas, respondendo a toda questão social, a toda urgência, se consegue dimensionar a importância da escola, as abstrações sobre seu papel se encarnam na vida.

Por causa disso, ela é guiada por um impulso crítico que busca desafiar políticas e práticas sociais, econômicas e culturais que geram desigualdades nas condições materiais e sociais da vida dos indivíduos, limitando sua possibilidade de prosperidade. Ela busca tanto remover as barreiras que limitam a "liberdade individual e a democracia do poder coletivo" quanto iluminar os possíveis caminhos para construir políticas e práticas mais responsáveis (APPLE, 2017, p. 248).

A aproximação entre a comunidade e a escola, é antes de tudo uma metodologia de ensino aprendizagem, factível e próxima do trabalho educativo do professor e da professora, não é uma idealização distante da sala de aula e das realidades brasileiras. Essa possibilidade reforça o papel político e autonomia do/a professor/a, habilitando um trabalho educativo multidisciplinar, ao mesmo tempo em que empodera e transforma a comunidade. Aulas que integrem conteúdos disciplinares e contextos sociais imediatos, ganham em qualidade e interesse, melhorando significativamente as condições de trabalho e satisfação na docência, diminuem a evasão e reprovação escolar, remédio para muitos males. Agora a cereja do bolo, quanto maior for a satisfação docente no ensino, menores serão seus problemas de saúde profissional.

\section{A formação docente e a importância da diversidade na escola}

Abordaremos propositiva e criticamente a formação docente das professoras e professores, a partir do contexto e experiência formativa paranaense, o que em termos comparativos, não se distancia significativamente do restante do país. Também nos utilizamos de pesquisas e ações extensionistas realizados entre os anos de 2015-18, destes o Projeto Tecnologias e Linguagens para o ensino de História - Fundação Araucária, entrevistou cerca de 30 docentes da rede pública de ensino do Estado do Paraná, na cidade de União da Vitória. O projeto de extensão, Gênero, educação e 
Sexualidades: reconhecendo diferenças para superar [pré] conceitos - USF (Universidade Sem Fronteiras-PR), atendeu a comunidade escolar em EJAS - Escolas de Jovens e Adultos, nos municípios paranaenses de São Mateus do Sul, General Carneiro, Bituruna, Paula Freitas e União da Vitória.

A discussão apresenta dois aspectos centrais, o primeiro é a formação universitária, seja nas licenciaturas ou bacharelados, que apesar de organizações curriculares e áreas de ação distintas, convergem em relação aos limites e problemas na formação docente. $\mathrm{O}$ segundo infere sobre a formação continuada dos/as docentes da educação básica paranaense, buscando traçar uma análise das condições atuais. A imensa maioria dos/as docentes entrevistados/as ou assistidos/as pelos projetos de pesquisa e extensão supracitados, deixa clara, pontual e inegavelmente o distanciamento entre a universidade e a educação básica, ainda que tenham cursado instituições superiores distintas e em tempos diferentes. O problema é apontado como central, pois não reconhecem a contribuição da universidade para sua formação e trabalho como professores, em resultado não criam ou desenvolvem canais de aproximação comum, além de apontarem que é a universidade que acaba por produzir o conteúdo científico escolar dos livros didáticos, processo ao qual não participam e que acabam exercendo na docência, passam a "embalar Mateus", numa referência ao ditado popular.

A universidade em sua criação celebrou o imperativo da ciência, do pensamento científico, da especialização do conhecimento, isso muito em função da Revolução Científica que fundou a universidade moderna e muito contribuiu com a sociedade mundial. O desenvolvimento da pesquisa e sua excelência singularizaram e direcionaram esforços, recursos e interesses, deixando o problema do ensino para os cursos de educação e psicologia. O ensino, didática e metodologias se tornaram um conhecimento acessório e vinculativo, não uma área de conhecimento e pesquisa própria. Mesmo com a abertura democrática no Brasil nos anos 80 e toda uma renovação educacional, com novos projetos e novos horizontes na educação brasileira, pouco se fez em relação ao ensino na universidade brasileira. Exceção clara surgiu com as associações de professores e professoras e a criação de grupos de pesquisa sobre ensino, didática e suas metodologias (SAVIANI, 2013).

A formação universitária é vista pelos professores e professoras como excessivamente teórica e pouco significativa nas condições de ensino-aprendizagem da educação básica. Alguns/mas docentes entrevistados falam da necessidade de reaprender a ensinar História, quando no começo de suas carreiras, e das dificuldades 
que os acompanham. As referências feitas sobre a formação universitária, no caso da maioria dos/as entrevistados/as uma licenciatura, vão em direção a um conhecimento abstrato, teórico, pouco palpável e pouco utilizável nas salas de aula. Além disso, as diferenças de ensino na forma, duração, avaliação e desempenho realizados entre a universidade e a educação básica são significativas, pouco podendo os professores e professoras da educação básica reproduzir aquilo que estavam acostumados a fazer e a desenvolver nas aulas da licenciatura enquanto alunos e alunas. O descompasso posterior entre as formas de fazer e a reflexão metodológica da licenciatura reforçam as dificuldades de apropriação de método e a objetivação de resultados; na indefinição entre o que aprenderam e o que precisam fazer, criam para si modelos de ensino próprios próximos em termos de método e resultado.

\begin{abstract}
A universidade muito próxima à pesquisa historiográfica, critério de sua formação e do próprio desenvolvimento da carreira universitária, não perspectiva outros lugares para si. A educação básica e seus professores, formados em outros contextos, buscam responder dentro do ensino a suas necessidades e fragilidades, não encontrando na universidade, com raras exceções, possibilidades de orientação e cooperação conjunta, pois as formas de pensar também são formas de fazer e de viver (CREMA, 2019, p. 157).
\end{abstract}

A formação continuada é parte do processo educacional e tem estatuto e importância assegurada na Lei de Diretrizes e Bases da Educação Nacional (LDB), n. 9.394/96, e no Plano Nacional de Educação (PNE), Lei n. 13.005/14 de 25 de junho de 2014 - 2024. Na LDB a formação continuada garante: I - a presença de sólida formação básica, que propicie o conhecimento dos fundamentos científicos e sociais de suas competências de trabalho; II - a associação entre teoria e práticas, mediante estágios supervisionados e capacitação em serviço e III - o aproveitamento da formação e experiências anteriores, e, instituições de ensino e em outras atividades. Ainda que existam fortes críticas aos documentos em sua perspectiva utilitarista, baseada na "pedagogia das competências", podemos perceber a importância e centralidade da formação continuada para os professores da Educação Básica, respaldada nos documentos e garantidos em leis.

A condição dinâmica do conhecimento moderno em suas mudanças e disputas exige da educação e seus trabalhadores e trabalhadoras, constantes formações, cursos e treinamento. Não obstante, segundo Saviani (2008), se considerarmos a história recente da educação brasileira percebemos uma sucessão, descontinuidade e sobreposição 
curricular, que em grande medida, afastou o interesse docente de sua discussão e do necessário domínio e conhecimento sobre os documentos de ensino. Precisamos lembrar que dominar teórica e metodologicamente uma orientação curricular, exige esforços significativos dos professores e professoras, a menos que as mudanças curriculares sejam vistas exclusivamente como um formalismo burocrático, distante do ensino na sala de aula. Ante as mudanças curriculares e a ausência de formações continuadas efetivas e periódicas, como no caso paranaense e não diferente em grande parte do Brasil, cabe aos professores e professoras reforçarem o campo prático e a experiência docente como mecanismos compensatórios e orientadores do trabalho docente, pois as necessidades de ensinar do trabalho docente, se apresentam em continuadas demandas. Segundo a fala de docentes entrevistados/as:

Talvez por eu ser essa geração que me formei, pensando na questão da estrutura do ensino seriado, e eu não tive nenhuma formação específica depois sobre outras formas da gente organizar o currículo, eu vejo que tem essa importância da gente organizar o currículo na estrutura que tá aqui no estado do Paraná, principalmente no que diz respeito à aproximação da história local (Professor 03).

Ai, que tema legal de se tratar! Eu acho muito carente a formação dos professores, a continuidade da formação dos professores, eu acho muito carente isso. Eu, dez anos de experiência, tudo o que essas formações que a gente tem é nada daquilo que a gente já não sabia. Não tem nenhuma novidade, você fica na expectativa de que vai vim uma coisa diferenciada, que você precisa ali, e sempre a mesma coisa. $\mathrm{Eu}$ acho falta, eu sinto muita falta dessas formações, é necessidade nossa atualizar, é necessidade da gente. Então eu acho carente, nós somos carentes (Professora 11).

Nos depoimentos docentes e em relação a experiência paranaense se constatou que as últimas formações continuadas efetivas, ou de resultado, aconteceram no ano de 2013, nos anos seguintes as semanas de formação continuada foram perdendo seu caráter formativo em direção a reuniões administrativas. Atualmente as "formações continuadas" acontecem duas vezes por ano no início dos semestres, com temas amplos e abrangentes, pouco significativos na fala dos professores e professoras, que escapam as necessidades formativas disciplinares, com contribuições questionáveis para o processo educativo. Entre as professoras e professores de história entrevistados sobre as principais carências e dificuldades relacionadas a temas e conteúdo de trabalho, apontaram a História do Paraná, História Afro-Brasileira, História Indígena e a diversidade e as relações de gênero, em menor número, acreditamos que a abordagem 
transversal das relações de gênero tenha contribuído com essa percepção, todas as áreas na visão dos professores e professoras carecem de materiais, conteúdos didáticos e domínio de metodologias de ensino.

Outrossim, e na direção apontada pelos/as docentes, as dificuldades de ensino espelham à importância das temáticas assinaladas, questões que exigiram dos entes federativos sua regulamentação em leis federais e estaduais, seja a Lei n. 10.639/2003, para o ensino da cultura e história afro-brasileira e indígena, seja a Lei Estadual $\mathrm{n}$. 13.381/01, que versa sobre a obrigatoriedade do ensino da História Regional do Paraná. A temática da diversidade sexual e as relações de gênero, ainda não contam com uma legislação educacional específica, entretanto são conteúdos contemplados nos Parâmetros Curriculares Nacionais (PCNs), dentro do tema transversal "orientação sexual", nas Diretrizes Curriculares Nacionais e em diversos pareceres e resoluções. Claro resta a importância fundamental e determinante que a escola e a educação brasileira vêm referendando em relação a diversidade sexual, as relações de gênero e toda a diversidade que existe e reivindica dentro da escola um espaço de legitimidade.

A diversidade em todas as suas dimensões é uma das bandeiras mais importantes em toda a história recente da educação brasileira e precisa ser ensinada a nossas alunas e alunos. Precisamos naturalizar e socializar as discussões sobre a diversidade, relações de gênero e relações étnico raciais, em grau e em condição que nossos/as discentes se utilizem do aprendizado e da necessária empatia sobre a diversidade aprendida na escola, para compreender e transformar a si próprios/as e a sociedade em que vivem. Sobretudo, combater as formas tradicionais, retrógadas e conservadoras pelas quais a diversidade é negada e condenada. Evidentemente que a escola deve se abrir verdadeiramente para a discussão sobre as diversidades, nossos professores e professoras precisam dominar de forma suficiente os conteúdos, formas de abordagem e metodologias de ensino adequadas, sobretudo, devem estar abertos/as ao campo. Criticamente:

Tais inquietações não podem passar despercebidas. É preciso que se pense em uma formação que dê conta de esclarecer as dúvidas sobre gênero e diversidade sexual. E quando digo formação, penso na responsabilidade dos cursos de formação docente, magistério e cursos de graduação em licenciaturas e na formação continuada de docentes. Nos cursos de licenciatura o tema só é debatido se no colegiado do curso há professores/as que estudam o tema e oferecem disciplinas optativas, dificilmente a temática compõe a matriz disciplinar. $\mathrm{Na}$ formação continuada há uma diversidade de cursos sendo oferecidos, infelizmente esses cursos atingem somente os interessados no tema e 
não toda a escola e é preciso pensar em estratégias que supram a carência escolar no entendimento do tema (ESTACHESKI, 2016, p. 72).

Se defendemos que o ensino dos conteúdos científicos e seus conhecimentos escolares podem e são melhor ensinados e aprendidos quando relacionados às experiências e conhecimento social dos alunos e alunas, consideramos producentemente que o inverso é verdadeiro. Precisamos habilitar um conhecimento escolar científico, ético - humanista que garanta uma explicação/compreensão suficiente para nossos alunos e alunas, suprindo suas carências de orientação da vida prática. Se as narrativas aprendidas/construídas sobre a diversidade dentro da escola, auferirem uma qualidade explicativa/compreensiva superior, ao senso comum e preconceito presentes na sociedade, nossos alunos e alunas construirão uma criticidade explicativa modelar, transformando a própria realidade, ou no mínimo desenvolverão parâmetros compreensivos mais coerentes.

O debate e o ensino das diversidades devem acontecer desde as séries iniciais e necessita ser encampado por todas as disciplinas escolares, pois em termos sociais as crianças convivem precocemente com diversas formas de preconceito, violência e marginalização, e precisam de um contraponto do conhecimento escolar, de discursos de respeito, valorização e tolerância, ressignificando suas experiências sociais e culturais em novas narrativas. Entretanto, atualmente as realidades das escolas brasileiras, fortemente pressionadas por grupos conservadores, são de esvaziamento e negação de conteúdo, debates e reflexões sobre as diversidades étnicas, sociais e sexuais, inclusive com tentativas de criminalização, controle de conteúdo e fim da liberdade de cátedra dos professores e professoras.

A separação cria naturalmente um problema de integração e relação dos modelos e tipos de conhecimento, pois quando a realidade do aluno não é comtemplada nos conteúdos escolares formais, em decorrência e insuficiência, os conhecimentos escolares também não se farão presentes, no cotidiano e na vida prática dos alunos(as) (CREMA, 2016, p. 58).

Mas o que a escola vem fazendo quando ensina? Ainda vemos uma significativa disciplinarização dos conteúdos científicos escolares, pouco articulados a experiência social e cultural de nossos alunos e alunas. Os modelos formais e científicos do conhecimento negam as categorias sociais do conhecimento, como a vivência a senciência, memória, oralidade, entre outras, estruturando uma sistematização e 
homogeneização do ensino que vai na direção contrária dos saberes cotidianos e das carências de orientação de nossos alunos e alunas. Em termos práticos, quem de nós nunca questionou a validade, funcionalidade, ou mesmo, o uso do que aprendia. Falamos como alunos/as e como professores/as escutamos com certa frequência as seguintes frases: Para que serve esse conteúdo? Para que eu preciso aprender isso? Onde vou usar isso? Indagações que por mais inocentes possam ser, apontam claramente os problemas e o limites de um ensino de conteúdos escolares exclusivamente científicos. Se nós professores e professoras não sabemos responder a perguntas tão simples e verdadeiras, precisamos rever nossas formas de aprender e ensinar. Ressalvamos que não estamos negando a ciência, mas sim os processos metodológicos de ensino que se distanciam das estruturas sociais do conhecimento.

\begin{abstract}
A separação cria naturalmente um problema de integração e relação dos modelos e tipos de conhecimento, pois quando a realidade do aluno não é contemplada nos conteúdos escolares formais, em decorrência e insuficiência, os conhecimentos escolares, também não se farão presentes, no cotidiano e na vida prática dos alunos(as). Nossos alunos não foram ensinados, sobretudo, foram desestimulados, a utilizarem e relacionarem o conhecimento científico com o conhecimento cotidiano, deixando de produzir uma síntese (CREMA, 2016, p. 58).
\end{abstract}

$\mathrm{Na}$ ausência de uma abordagem mais pragmática do ensino e seus conteúdos e do crescente distanciamento que as seriações escolares promovem durante a vida escolar dos conhecimentos e experiências sociais, temos como resultado uma forte “didatização" geral do processo de ensino-aprendizagem escolar, numa formulação mecânica e universal do saber, etapas de um processo linear, não dialógico. Os processos de organização e controle do conhecimento escolar em seu ensino, buscam otimizar os saberes postos dentro dos conteúdos científicos, como se natural e equivalentemente esses saberes, essas informações se explicassem em sua existência, funcionalidade e origem. Não é à toa que muito do que aprendemos, sequer sabemos a que serve e por consequência pouco uso fazemos. Não basta apresentarmos um conteúdo científico ou uma forma de saber sem relacioná-lo aos contextos da vida prática, tanto naquilo que o originou, quanto naquilo a que se destina.

Até o início da escolarização, nas séries iniciais do Ensino Fundamental, as crianças vivenciam um significativo e continuado processo de compreensão, aprendizado e sistematização do conhecimento social. Nas escolas, e em consequência da cultura escolar, os conhecimentos sociais e suas formas de compreensão e relação, 
são sistemática e continuadamente marginalizados ou negados pela escola, contrariando a experiência e expectativa dos alunos e alunas. A vivência e o cotidiano como forma e modelo de aprendizagem são gradualmente e repetidamente substituídas por conhecimentos científicos escolares disciplinares em níveis sequenciais singularizados, entrando em conflito com as formas de compreensão historicamente construídas pelas crianças. "Também, podemos apontar que modelos educacionais, que se constroem fora da realidade histórica do aluno, tendem a reproduzir o distanciamento e a irrealidade, também no conhecimento formal/tradicional" (CREMA, 2016, p. 57).

Notadamente a escola não detém a exclusividade sobre as formas de se produzir conhecimento e processos de aprendizagem, todavia, a escola possui a hegemonia dos processos formais de produção, reprodução e transmissão cultural do conhecimento, seja pela alfabetização, letramento matemático e qualquer outra área do conhecimento. Entretanto as escolas dispõem desse conhecimento dentro de estruturas e metodologias de ensino/aprendizagem, técnica e metodologicamente construídas, lugar e interesse da pedagogia. Acertadamente os conhecimentos e saberes científicos ensinados nas escolas devem observar as condições funcionais e pré-ativas postas no viver, nas formas de lazer, na cultura e linguagens populares em direção ao conhecimento escolar, não como fim, mas como meio, pois a síntese do conhecimento escolar deve voltar-se propositiva e resolutivamente para a sociedade, validando e justificando o próprio campo escolar.

\section{Experiência, preconceito e humanismo}

Por definição conhecimento é o ato de conhecer; perceber ou compreender por meio da razão e ou experiência, condição inerente ao ser humano, fundamental na orientação da vida prática. Do pensamento mais complexo às ideias cotidianas mais simples, somos impelidos/as pelo passado a desenvolver perspectivas normativas orientando o agir. Nossa necessidade de ação na vida, exige e cria expectativas subjetivas potenciais que conformam a identidade individual, determinando os interesses pessoais e leituras de mundo. A identidade e interesse criam um entendimento sobre o viver, onde a ação é a extensão natural do existir, que ameaçada se torna uma cominação ao ser. Dessa forma, a alteridade e a diferença podem ser vistas como algo negativo, pois a sociedade criou e desenvolveu comportamentos, práticas, costumes e valores em pretensa homologia, buscando na ideia de comunidade a identidade comum, 
uma estrutura de autopreservação. A relação entre o eu idealizado e o outro, desenvolve uma assimetria reforçada, positiva em mim, nós e negativa nos/as outros/as.

O pensamento etnocêntrico projeta, na alteridade dos outros, aquelas propriedades que o sujeito considera problemáticas ou até insuportáveis, na formação de sua identidade. O sujeito se livra, assim, do peso de suas próprias insuficiências. Tal banimento das zonas sombrias do passado próprio, no entanto, não suprime a alteridade, sentida como um desafio ou mesmo ameaça ao próprio eu, sobretudo quando esse se imagina transparente e puro (RÜSEN, 2015, p. 267).

Para Rüsen (2015) são as representações do passado que orientam o futuro, através da cultura histórica, buscando lidar com o problema da mudança/permanência e da diferença/igualdade em seus resultados sociais. Essa tensão natural produz um conflito latente entre estruturas e condições de mudança e manutenção, não do tempo mutável, mas das representações do passado postas no presente a realizar-se. Essa pequena digressão explica em parte os motivos pelos quais o pensamento conservador/tradicional busca "imobilizar" o passado e "eternizar" o presente, em direção ao controle das estruturas sociais, do conhecimento, da moralidade, comportamento, sexualidade e raça, por exemplo. Modernamente a alteridade e a diversidade são vistas como realidades extremamente positivas, reflexo de novas experiências e arranjos históricos que se aceleraram ao final da Segunda Guerra Mundial e ao processo de globalização em todas as suas dimensões. "A globalização instaura uma proximidade que requer novas formas de diferenciação do outro" (RÜSEN, 2015, p. 269).

Com o crescimento das possibilidades de distinção e diferenciação entre os indivíduos em proximidade, as premissas de homogeneização das identidades em seu limite, vão dando lugar as pluralidades e diversidades como mecanismos relacionais e de reconhecimento. Rüsen defende que a dimensão humana partilhada conceitualmente na diferença e não mais na igualdade, criaria uma evolução cultural da humanidade. $O$ reconhecimento universal da "diferença comum" cria uma premissa conceitual onde todos são iguais por suas diferenças, atualizando a cultura histórica para um novo paradigma, um "humanismo diverso". Ao mesmo tempo romperia com as teleologias míticas das origens em seu imobilismo, situando no futuro, a realizar-se a partir da própria realidade histórica em sua mudança, diferença e diversidade. Nessa perspectiva o etnocentrismo perde sua função dentro da cultura histórica, superado pelos novos arranjos de um modelo "policêntrico", mas representativo e tolerante para com o 
diferente, pois as categorias conceituais de identidade dão lugar a conceitos de autorepresentação vividos na diversidade.

No âmbito de tal pensamento histórico rompe-se também a perspectiva autocentrada do pensamento etnocêntrico. A própria história de cada um ingressa na pluralidade de inúmeras perspectivas, que se relacionam discursivamente no jogo reciproco da crítica do reconhecimento. Abrem-se assim chances de entendimento intercultural no nível profundo dos processos de formação de identidade, no plano da história cultural' (RÜSEN, 2015, p. 271).

Nesse sentido, a escola cumpre um importante papel em termos de transmissão e transformação cultural, não somente por suas obrigações institucionais e sua relação com a educação e o conhecimento, mas porque também é um dos espaços sociais mais diversos e representativos, capaz de "reconstruir" o pensamento de nossos/as jovens em direção a uma sociedade mais justa, democrática e equitativa. Não à toa que a educação, professores/as e a universidade brasileira vem sofrendo ataques coordenados por setores, instituições, grupos e partidos políticos conservadores, que negam a diversidade étnica, sexual e as relações de gênero, buscando espelhar impositivamente no corpo social seus referenciais indentitários, suas visões de mundo. Perspectivas que vão contra os direitos humanos, a liberdade e os direitos individuais, na contramão da ética e ao arrepio da Lei. Defender a liberdade e legitimidade do ensino das diversidades dentro das escolas, é sobretudo um imperativo categórico necessário para o pensamento crítico, e a permanência da escola como um lugar de diversidade e da tolerância, um farol para o bom, o belo e o verdadeiro.

As pressões que a educação brasileira vem sofrendo mostram claramente a condição formadora da escola, reforçam o compromisso ético do conhecimento para com a sociedade. A ciência não pode submeter a pessoa à sua racionalização, o pensamento científico deve habilitá-la em sua essência, já que o conhecimento serve à humanidade, que seus saberes celebrem a vida, a tolerância e a diversidade. Não é o ensino das relações de gênero, sexualidades e diversidades o problema em nossas escolas, nossos problemas são a discriminação, a violência em todas as suas formas, a indiferença e a intolerância. Sim, esses são problemas que requerem enfrentamento, que necessariamente precisam de conhecimento, de saberes que desconstroem a discriminação e semeiam a mudança.

Nossa sociedade machista e heteronormativa não quer admitir a dignidade de outros sujeitos e deseja calar quem luta pela não 
violência de gênero, pois isso subverte a ordem das coisas. A culpabilização das vítimas por violência doméstica, por violência sexual, por homofobia corrobora com um discurso equivocado de moralidade e religiosidade que favorece agressores. O debate sobre gênero pode romper com a ideia instituída de que a culpa pelo estupro sofrido é da vítima e não do agressor, de que a culpa pela morte violenta é da travesti que não se adequou à regra imposta, e com a ideia de que é por não adequarem-se que homossexuais deveria se esconder e não ter direito a estudo, vida e dignidade, para não escandalizarem as pessoas que não conseguem ver humanidade nas outras pessoas (ESTACHESKI, 2016, p. 72).

Precisamos olhar para os processos, históricos, seus personagens compreendendo e contextualizando sua historicidade, não porque ao estarem no passado evocam formas de compreensão tradicionais, mas porque pela experiência vivida, conformam estruturas narrativas compreensivas coerentes com a humanidade em sua trajetória. A história não pode ser concebida por um relativismo radical, como se o próprio percurso histórico e seu conhecimento, nada mais fossem, do que um evento aleatório percebido no presente. A história em resultado é arbitrada e validada no tempo presente por sua coerência, moralidade e plausibilidade, atribuindo valor a ação humana, para Martin Luther King:

[...] cada dia é o dia do julgamento, e nós, com nossos atos e nossas palavras, com nosso silêncio e nossa voz, vamos escrevendo continuadamente o livro da vida. A luz veio ao mundo e cada um de nós deve decidir se quer caminhar na luz do altruísmo construtivo ou nas trevas do egoísmo. Portanto, a mais urgente pergunta a ser feita nesta vida é: O que fiz hoje pelos outros?

\section{Referências}

APPLE, Michael Whitman. A educação pode mudar a sociedade. Petrópolis, RJ: Vozes, 2017.

BRASIL. Diretrizes Curriculares Nacionais para a Educação Básica. Brasília, DF: MEC, 1996.

BRASIL. Ministério de Educação e Cultura. Lei de Diretrizes e Bases da Educação Nacional. Lei n. 9394/96, de 20 de dezembro de 1996. Estabelece as diretrizes e bases da Educação Nacional. Brasília, DF: MEC, 1996.

BRASIL. Plano Nacional de Educação. Lei n. 13.005/14 de 25 de junho de 2014 2024. Brasília: Senado Federal, UNESCO, 2001.

BUENO, André da Silva; ESTACHESKY, Dulceli Tonet; CREMA, Everton Carlos. Gênero educação e sexualidades: reconhecendo diferenças para superar [pré] conceitos. Uberlândia: Ed. dos Autores, 2016.

CANCLINI, Néstor Garcia. Culturas híbridas. São Paulo: Edusp, 2015. 
CREMA, Everton Carlos. Currículo, cultura histórica e cultura escolar na construção estética da aula. 2019. 220f. Tese (Doutorado em Educação) - Universidade Federal do Paraná. Curitiba. 2019.

CREMA, Everton Carlos. Rüsen e o "novo humanismo" reflexões para a educação e a diferença. In: BUENO, André da Silva; ESTACHESKY, Dulceli Tonet; CREMA, Everton Carlos. Gênero educação e sexualidades: reconhecendo diferenças para superar [pré] conceitos. Uberlândia: Ed. dos Autores, 2016.

ESTACHESKI, Dulceli Tonet. Gênero na escola sim, mas como fazer? In: BUENO, André da Silva; ESTACHESKI, Dulceli Tonet; CREMA, Everton Carlos. Gênero educação e sexualidades: reconhecendo diferenças para superar [pré] conceitos. Uberlândia: Ed. dos Autores, 2016.

FORQUIN, Jean Claude. Escola e cultura: as bases epistemológicas do conhecimento escolar. Porto Alegre: Artes Médicas, 1993.

GOODSON, Ivor Frederick. As políticas de currículo e de escolarização. Petrópolis, RJ: Vozes, 2008.

KING, Martin Luther [citação].

PROJOTA. Ser melhor. São Paulo: Universal, 2016. Disponível em: https://www.youtube.com/watch?v=fXpX1Td63N4. Acesso em 1 jun. 2016.

RÜSEN, Jörn. Teoria da História: uma teoria da história como ciência. Curitiba: Editora UFPR, 2015.

SAVIANI, Demerval. História das ideias pedagógicas no Brasil. Campinas, SP: Autores Associados, 2013.

SAVIANI, Demerval. Desafios da construção de um sistema nacional articulado de educação. Revista Trabalho, Educação e Saúde, Rio de Janeiro, v. 6, n. 2, p. 213-232, out. 2008.

SCHMIDT, Maria Auxiliadora; MARTINS, Estevão de Rezende (org.). Jörn Rüsen: contribuições para uma teoria da didática da história. Curitiba: W. A. Editores, 2016. 